\title{
American Thyroid Association Scientific Statement on the Use of Potassium lodide Ingestion in a Nuclear Emergency
}

\author{
Angela M. Leung, ${ }^{1,2}$ Andrew J. Bauer, ${ }^{3,4}$ Salvatore Benvenga, ${ }^{5,6}$ Alina V. Brenner? \\ James V. Hennessey, James R. Hurley, Stacey A. Milan, ${ }^{9}$ \\ Arthur B. Schneider, ${ }^{11}$ Krishnamurthi Sundaram, ${ }^{12}$ and Daniel J. Toft ${ }^{13}$
}

This document serves to summarize the issues and the American Thyroid Association (ATA) position regarding the use of potassium iodide as a thyroid blocking agent in the event of a nuclear accident. The purpose is to provide a review and updated position statement regarding the advanced distribution, stockpiling, and availability of potassium iodide in the event of nuclear radiation emergencies in the United States.

Keywords: potassium iodide, KI, nuclear emergency, nuclear power plant, predistribution

\section{INTRODUCTION}

$\mathbf{T}$ The American Thyroid Association (ATA) has long been an advocate for the use of potassium iodide (KI) as a thyroid blocking agent in the event of a nuclear accident (1). In 2002, the ATA issued a statement on the use of KI in the event of a nuclear power plant accident that was co-endorsed by the American Association of Clinical Endocrinologists, the Lawson Wilkins Pediatric Endocrine Society, and the Thyroid Foundation of America (2). Since then, there are new data in the aftermath of the release of radioactive iodine $\left({ }^{131} \mathrm{I}\right)$ from the Fukushima nuclear reactors (3); the National Academy of Sciences' 2004 report on KI use (4); evolving policies in the United States and internationally; and many peer- reviewed publications (5), including updated data from the Chernobyl accident.

In this statement, "predistribution" is referred to as the supply of KI directly to individuals in the general population within a defined area surrounding an operating nuclear power plant. Presumably, in all cases, KI will also be available (i.e., stockpiled) within the same area. "Stockpiling" is defined as the availability of KI at key locations sufficient to protect the local population, such as schools, hospitals, clinics, post offices, pharmacies, and police and fire stations within a larger defined area around an operating nuclear facility. Included in this term is inclusion of KI in the U.S. Public Health Emergency Medical Countermeasures Enterprise (PHEMCE) (6) and similar programs. The organization of this Statement can be found in Table 1.

\footnotetext{
${ }^{1}$ Division of Endocrinology, Diabetes, and Metabolism, Department of Medicine, UCLA David Geffen School of Medicine, Los Angeles, California.

${ }^{2}$ Division of Endocrinology, Diabetes, and Metabolism, Department of Medicine, VA Greater Los Angeles Healthcare System, Los Angeles, California.

${ }^{3}$ Division of Endocrinology and Diabetes, Children's Hospital of Philadelphia, Philadelphia, Pennsylvania.

${ }^{4}$ Department of Pediatrics, The University of Pennsylvania, The Perelman School of Medicine, Philadelphia, Pennsylvania.

${ }^{5}$ Department of Clinical and Experimental Medicine, University of Messina School of Medicine, Messina, Italy.

${ }^{6}$ Interdepartmental Program of Molecular and Clinical Endocrinology and Women's Endocrine Health, University hospital Policlinico G Martino, Messina, Italy.

${ }^{7}$ Division of Cancer Epidemiology and Genetics, Department of Health and Human Services, National Cancer Institute, National Institutes of Health, Bethesda, Maryland.

${ }^{8}$ Department of Endocrinology, Beth Israel Deaconess Medical Center, Boston, Massachusetts.

${ }^{9}$ Division of Endocrinology, Diabetes, and Metabolism; Joan and Sanford I. Weill Department of Medicine; Weill Cornell Medical College, New York, New York.

${ }^{10}$ Department of General Surgery, Division of Endocrine Surgery, Texas Tech University Health Sciences Center, El Paso, Texas.

${ }^{11}$ Section of Endocrinology, Diabetes and Metabolism; University of Illinois College of Medicine, Chicago, Illinois.

${ }^{12}$ Department of Otolaryngology, SUNY Downstate Medical Center, Brooklyn, New York.

${ }^{13}$ Division of Endocrinology, Department of Medicine, Feinberg School of Medicine, Northwestern University, Chicago, Illinois.
} 
Table 1. Organization of the Statement

\section{BACKGROUND}

1. Where are the currently operating nuclear power plants in the United States and internationally?

2. What are the current recommendations regarding potassium iodide (KI) use and predistribution?

A. What are the recommendations for KI use and predistribution in the United States?

B. What are the recommendations for KI use and predistribution in Europe?

3. What are the mechanisms in place for state-specific adherence to U.S. federal recommendations?

4. What are the available options for timely communication to the public following a nuclear emergency?

THYROID DISEASE RISKS AND OTHER HEALTH EFFECTS OF RADIOACTIVE IODINE $\left({ }^{131}\right.$ I) EXPOSURE FOLLOWING A NUCLEAR EMERGENCY

5. What are the main risks regarding nuclear emergencies?

6 . What are the potential routes of ${ }^{131}$ I isotope exposure following a nuclear reactor emergency?

7. What have been the thyroid and other adverse health effects resulting from nuclear accidents in the past?

A. Three Mile Island (March 28, 1979)

B. Chernobyl (April 26, 1986)

C. Fukushima (March 11, 2011)

KI PLANNING AND INGESTION DURING A NUCLEAR EMERGENCY

8. What is the effectiveness of KI ingestion in decreasing thyroid exposure to ${ }^{131} \mathrm{I}$ isotopes and subsequent thyroid cancer incidence following a nuclear emergency?

9. What other mechanisms besides KI prophylaxis are recommended to decrease radiation exposure following a nuclear emergency?

10. When and at what doses should KI be ingested following a nuclear emergency?

11. What forms of KI are currently available in the United States?

12. What are the major reasons for and against the predistribution of KI to be consumed in the event of a nuclear emergency?

13. What is the evidence guiding the deployment of KI, including KI predistribution, at various distances around operating nuclear power plants?

14. What are the potential risks of KI use following a nuclear emergency?

15. What are the recommendations of the American Thyroid Association for the distribution and use of KI in the event of a nuclear emergency in the United States?

\section{BACKGROUND}

\section{Where are the currently operating nuclear power plants in the United States and internationally?}

There are 31 countries currently operating nuclear power plants, which together account for approximately $4.4 \%$ of global energy production (7). The United States, France, Russia, South Korea, and China generate more than twothirds of the total nuclear energy produced globally. More nuclear power is generated in the United States than in any other country, where nuclear power accounts for $19.5 \%$ of U.S. electricity needs (8). Of the 446 operational powergenerating reactors worldwide, 100 are located in the United States (8). A complete list of operational and decommissioned power-generating reactors is published online by the International Atomic Energy Association (8). In the United States, the vast majority of reactors can be found east of the Mississippi River. In addition to the 100 power-generating reactors in the United States, there are 31 research and test reactors found mainly at universities that are spread more evenly across the United States $(9,10)$. To conserve the cost of transporting nuclear-generated electricity, most reactors are located proximal to those consuming energy. Approximately $38 \%$ of the U.S. population resides within 50 miles of a reactor (11). The average age of the American reactors was 28.8 years in 2015 , one third of which were older than the 40 years of operation that they were initially designed to withstand (7).

\section{What are the current recommendations regarding $\mathrm{KI}$ use and predistribution?}

\section{A. What are the recommendations for KI use and predistribution in the United States?}

Under the Public Health Security and Bioterrorism Preparedness and Response Act of 2002, U.S. legislation mandated that all areas within a 20 -mile radius of an operating nuclear power plant have a KI distribution program in place in the event of a nuclear emergency (12). Predistribution of KI was not required in these policies. Furthermore, the legislation allowed the executive branch to reduce the radius to 10 miles, which it subsequently did. This legislation also allowed states with nuclear power plants to obtain KI stores from federal sources if they deemed it to be appropriate. However, in 2008, Dr. John H. Marburger III, Director of Science and Technology Policy under the Executive Office of the President, invoked a waiver provision in the legislation and eliminated the requirement that adequate quantities of KI necessary to protect all individuals within a 10-mile radius of a nuclear plant be available to state and local governments (13), a policy that continues currently. As such, the U.S. Nuclear Regulatory Commission (NRC) requires states to consider including $\mathrm{KI}$ as a protective measure, to be used along with evacuation, sheltering, and avoidance of contaminated foodstuffs, in the event of a nuclear accident (14).

The potential challenges with the predistribution of KI were emphasized by a recent analysis performed by the Center for Biosecurity of the University of Pittsburgh 
Medical Center (15). The following are adapted excerpts: "U.S. federal policy recommends that states consider stockpiling and distributing $\mathrm{KI}$ as an adjunct to evacuation. However, there are few plausible scenarios in which KI distribution from the stockpile could occur quickly enough to make a major difference in a community. During Fukushima, Japan made a preliminary request for KI from the U.S. stockpile, but it was eventually not needed. Little KI was administered to the Japanese population, whose diet is iodine-rich, as radiation thresholds for KI administration were not exceeded. The experience with Fukushima did, however, provide some foreshadowing of possible U.S. demand for KI: As the plume of radioisotopes released from the Japanese power plant blew across the Pacific, many in the U.S. began to demand KI."

In addition, the report stated that "U.S. federal policy should downplay use of KI and emphasize evacuation. A major concern is that KI instills a false sense of security among the population and that demand for KI might delay evacuation. For states that have already committed to KI distribution, it would be extremely difficult to move away from that position without a substantial investment in public education." Nevertheless, they arrive at a conclusion similar to the one of the ATA: "Given the likelihood that plans to provide (or predistribute) $\mathrm{KI}$ in the event of a nuclear accident will continue, it is paramount that the most important emergency response message is always: 'Evacuate first-do not waste precious time looking for KI or waiting for it'" (16). However, the dangers of evacuation should not be discounted, as discussed below.

On March 28, 2013, Congressman (now Senator) Edward J. Markey, the ATA, and others wrote to John P. Holden (Director, White House Office of Science and Technology Policy) supporting KI predistribution. The following is adapted from this letter: "We believe [the analyses of KI predistribution should use] ... the scenario assumed throughout the 2004 National Academy of Sciences (NAS) report 'Distribution and Administration of Potassium Iodide in the Event of a Nuclear Incident' (4) that the need for administration of KI is necessary only once to protect the thyroid gland against inhalation of radioiodine from a passing plume (cloud) and that further protection from radioiodine will be accomplished by evacuation and control of contaminated milk and other foods." It was also stated that "In other words, people at risk of exposure to radioactive iodine could be directed to take $\mathrm{Kl}$ as they evacuated, not as a substitute for evacuation." After considering these arguments, the ATA continues its strong support for the predistribution of KI in the United States.

\section{B. What are the recommendations for $\mathrm{KI}$ use and pre- distribution in Europe?}

Community legislation requires the European Union (EU) member states to prepare for nuclear and radiological emergencies and to intervene in order to protect the population from excessive radiation doses caused by accidental releases of radioactive substances (16). Most European countries have included the recommendation of KI ingestion in their emergency plans. KI is predistributed in all of the European countries that have a nuclear power plant (Table 2), although the radius for predistribution ranges from 5 to $50 \mathrm{~km} \mathrm{(3.1-}$ 31.1 miles) (16). In most cases, $\mathrm{KI}$ is delivered to the whole population, and stockpiling practices vary by country.

\section{What are the mechanisms in place for state-specific adherence to U.S. federal recommendations?}

Current recommendations by the U.S. NRC defer to the individual states with populations within the 10-mile emergency planning zone (EPZ) of commercial nuclear power plant to decide for their residents the appropriateness of KI distribution (14). In the current structure, states are able to review the appropriateness of their own emergency preparedness plans and request funding for state KI stores from the federal level if desired. Each individual state determines its own recommendation of whether to predistribute KI. As of August 3, 2016, 25 states have received KI tablets from the NRC (14).

\section{What are the available options for timely communication to the public following a nuclear emergency?}

Establishing clear, consistent, and continuous communication following a nuclear emergency is essential for public safety. Standard means of communication may be disrupted in an emergency due to electrical grid disruption from the nuclear emergency or from a precipitating natural disaster, and communication networks may be inaccessible due to the volume of attempted use. In the United States, all licensed nuclear power sites are required to prepare a plan "to ensure the delivery of understandable, timely, accurate, consistent, and credible information to the public, the media, and other stakeholders during a radiological emergency" (17).

As part of emergency preparedness, residents surrounding nuclear power sites and, in particular, vulnerable and migrant populations should be identified and be provided with radiation education in advance and be advised how to obtain information during an emergency. Emergency broadcasts via the Emergency Alert System using traditional media and cell phones, Web site updates, social media, news releases, and call centers (assuming these are uninterrupted and operational) should all be employed to reach the public with consistent information across media platforms in the languages prevalent in the population. The Internet and social media allow for real-time communication of events and news, which may serve as useful tools, but uncurated decontextualized news may negatively affect public health during a nuclear emergency. The U.S. NRC has detailed guidelines for establishing a "Virtual Joint Information Center" to be used by nuclear power plant operators in the event of an emergency to ensure effective mass communication (17).

\section{THYROID DISEASE RISKS AND OTHER HEALTH EFFECTS OF ${ }^{131}$ I EXPOSURE FOLLOWING A NUCLEAR EMERGENCY}

\section{What are the main risks regarding nuclear emergencies?}

- Risks of future nuclear emergencies: There is a continuing risk that nuclear power plant accidents will occur. Even though efforts had been made to protect power plants from potential earthquakes and tsunamis, 
Table 2. The Predistribution of KI in Europe*

\begin{tabular}{|c|c|c|c|}
\hline & Area for predistribution & $\begin{array}{l}\text { Target population } \\
\text { within predistribution } \\
\text { area }\end{array}$ & Method of distribution \\
\hline Belgium & $20 \mathrm{~km}(12.4$ miles $)$ & All & Pharmacies \\
\hline Czech Republic & $\begin{array}{l}\text { Dukovany NPP: } 13 \mathrm{~km} \text { (8.1 miles) } \\
\text { Temelin NPP: } 20 \mathrm{~km} \text { (12.4 miles; EPZ) }\end{array}$ & All & $\begin{array}{l}\text { NPPs are responsible } \\
\text { and local authorities } \\
\text { help organize }\end{array}$ \\
\hline Finland & $\begin{array}{l}5 \mathrm{~km}(3.1 \text { miles }) \text { : households and summer houses } \\
\text { Whole country: KI tablets kept in kindergartens } \\
\text { and schools }\end{array}$ & All & Mail \\
\hline France & $\begin{array}{l}10 \mathrm{~km}(6.2 \text { miles }) \text { around NPP } \\
2.5 \mathrm{~km}(1.6 \mathrm{miles}) \text { around facilities producing } \\
{ }^{131} \text { I for medical use }\end{array}$ & All & Pharmacies and mail \\
\hline Germany & $\begin{array}{l}0-5 \mathrm{~km}(0-3 \text { miles }) \text { : predistribution to all } \\
\text { households is recommended } \\
5-10 \mathrm{~km}(3.1-6.2 \text { miles }) \text { : either predistribution or } \\
\text { KI stores at several points in the municipality } \\
\text { (e.g., town hall, schools, hospitals, businesses }) \\
10-25 \mathrm{~km}(6.2-15.5 \text { miles): storing in the } \\
\text { municipality is recommended }\end{array}$ & All & $\begin{array}{l}\text { As per the } \\
\text { responsibility of } \\
\text { State authorities }\end{array}$ \\
\hline Lithuania & $50 \mathrm{~km}(31.1 \mathrm{miles})$ & All & By municipalities \\
\hline Luxembourg & Entire territory & $\begin{array}{l}\text { Parents for children } \\
<5 \text { years age }\end{array}$ & $\begin{array}{l}\text { Parents receive } \\
\text { individual packets } \\
\text { containing KI upon } \\
\text { birth of a child; KI is } \\
\text { also distributed to } \\
\text { parents with children } \\
<5 \text { years age }\end{array}$ \\
\hline Netherlands & $10-20 \mathrm{~km}(6.2-12.4$ miles $)$ & $<46$ years age & $\begin{array}{l}\text { Coordination is done by } \\
\text { pharmacies after } \\
\text { information by mail; } \\
\text { local authorities are } \\
\text { responsible for } \\
\text { execution. }\end{array}$ \\
\hline Romania & $10-30 \mathrm{~km}(6.2-18.6$ miles $)$ & All & $\begin{array}{l}\text { Free predistribution to } \\
\text { each family }\end{array}$ \\
\hline Slovakia & $\begin{array}{l}\text { Bohunice NPP: } 25 \mathrm{~km} \text { (15.5 miles) } \\
\text { Mochovce NPP: } 20 \mathrm{~km} \text { (12.4 miles) }\end{array}$ & All & $\begin{array}{l}\text { Taken at determined } \\
\text { point }\end{array}$ \\
\hline Sweden & $15 \mathrm{~km}$ (9.3 miles) & All & By mail \\
\hline Switzerland & $\begin{array}{l}20 \mathrm{~km} \text { ( } 12.4 \text { miles }) \text { to households, schools, and } \\
\text { working places }\end{array}$ & All & By mail \\
\hline United Kingdom & Around NPP (areas defined by the operator) & $\begin{array}{l}\text { Remote communities/ } \\
\text { schools/potential } \\
\text { rest centres }\end{array}$ & $\begin{array}{l}\text { Initially by Health } \\
\text { Protection Agency } \\
\text { nurse, then by mail. } \\
\text { KI tablets are free. }\end{array}$ \\
\hline
\end{tabular}

*Reference (16).

NPP, nuclear power plant.

the efforts were inadequate following such emergencies historically. It is not possible to predict the causes, setting, and timing of future nuclear accidents.

- Radiation risks: All accidental releases of radioactivity from operating nuclear plants can be expected to include ${ }^{131} \mathrm{I}$ and, invariably, a small amount of other radioiodine isotopes. Iodine is required for the production of thyroid hormones. As there are no chemical differences between stable and radioactive iodine, the thyroid cannot discriminate between the two and thus absorbs both from the circulation. This exposes the thyroid to a higher level of radiation than any other organ. The other major isotope that may be released from a nuclear accident is cesium-137 (Cs-137), al- though strontium-90 and plutonium-239 were also released following the Chernobyl accident. The ionizing radiation from this isotope may have immediate consequences, which further supports the recommendations for evacuation if possible. There is also concern for chronic, long-term radiation exposure from Cs-137 exposure, given its long half-life.

- Evacuation risks: The evacuation of the population in and around Fukushima was not without complications, including increased mortality (18). It is difficult to predict the complex issues that may be encountered during the evacuation process following any population-level emergencies, including potential loss of life (19). 


\section{What are the potential routes of ${ }^{131}$ I isotope exposure following a nuclear reactor emergency?}

Inhalation and ingestion are the two main routes of exposure to ${ }^{131} \mathrm{I}$ for humans following a nuclear reactor emergency. The primary route of exposure depends on an individual's distance from the reactor site at the time of a nuclear accident. Inhalation of radioactive products in the plume is the main route of exposure within an approximately 10-mile radius from the reactor. Outside of this 10-mile radius, the ingestion pathway becomes another important route of exposure (20).

During a nuclear reactor emergency, radioactive gases and particles (i.e., ${ }^{131} \mathrm{I}$ and $\mathrm{Cs}-137$ ) are released into the atmosphere and can be carried by the wind (21). The concentration of the radioactive contaminants in the plume will decrease as the plume travels due to dispersion and precipitation resulting from rain and snow. Based on previous nuclear reactor accidents (Chernobyl and Fukushima), there is evidence that the original plume may have extended $>300$ miles (22), although the main pathway of exposure at this distance was ingestion of contaminated food. Unpredictable and uncontrollable weather patterns, such as wind direction and precipitation, as well as the effects of the surrounding terrain, result in complex and variable exposure patterns from the plume on local populations following a nuclear reactor emergency (21).

In the ingestion pathway for exposure, radioactive materials are deposited (mainly because of rainfall) onto vegetation, including pasture grasses that are then consumed by cows and subsequently consumed by humans in the form of cow's (and goat's) milk and meat (21). Soil can also be contaminated and thus affects the ${ }^{131}$ I content in consumed foods, in addition to the deposition of radioactive material on the surface of the food. This affects foods such as leafy green vegetables, mushrooms, and berries $(21,23)$. Notably, infants and children are at increased risks of the negative effects of ${ }^{131}$ I due to their faster-growing thyroids, rapid breathing rate, and increased consumption of milk (24). Children also have increased expression of proteins involved in iodine metabolism, increased iodine transport, and an increased proliferation index in those $<12$ years of age $(25,26)$.

Also of concern is the ingestion of radioactive isotopes, including ${ }^{131} \mathrm{I}$, from water sources. These water sources may result from contamination by direct discharge of radioactive elements (i.e., seawater contamination following the Fukushima Daiichi accident) or by subsequent precipitation from the plume and runoff into freshwater sources, including drinking water, from contaminated soil and other surfaces (23). Radioactive products released directly into the ocean are thought to be rapidly diluted due to the large volume of water, and are dispersed quickly following pathways that are dependent on sea currents. Dilution of radioactive discharge into freshwater bodies depends on the size of the water body and distance from the nuclear reactor. Because of the relatively short half-life of ${ }^{131}$ I of eight days, the concentration of ${ }^{131} \mathrm{I}$ in fish became insignificant within a few months following the Chernobyl emergency (21).

As a result of flawed countermeasures after the Chernobyl accident, the consumption of milk that had been contaminated prior to distribution was the major route of exposure $(21,24)$. This was further complicated due to high numbers of private farmers in the affected areas to whom timely advice was not distributed regarding avoidance of contaminated foodstuffs (21). Shortly after the Fukushima accident, ${ }^{131} \mathrm{I}$ was detected in the drinking water of several towns and villages of varying distances, and was also detected in milk and leafy vegetables, mushrooms, and eel-like fish that exceeded the protective-action limits (15,23). On March 17, 2011 (six days after the event), the Ministry of Health, Labour, and Welfare of Japan directed that food and water contaminated above the protective limits should not be consumed, thereby reducing levels of exposure to the general public.

\section{What have been the thyroid and other adverse health effects resulting from nuclear accidents in the past?}

Three historical major nuclear power plant accidents have provided extensive insight into the lessons learned and challenges associated with protection of radioisotope exposure following a nuclear emergency (27).

\section{A. Three Mile Island (March 28, 1979)}

i. How much ${ }^{131}$ I was released into the atmosphere? A relatively small amount of ${ }^{131}$ I was released following the Three Mile Island accident. The estimated release was $13-17 \mathrm{Ci}$ (481-629 GBq) or $0.000003 \%$ of the ${ }^{131}$ I amount following the Chernobyl accident (28). ii. What was the response to the accident?

Two days after the accident, evacuation of pregnant women and children who were within $8 \mathrm{~km}$ ( 5 miles) of the reactor was advised. Eventually, about 200,000 people within a $24 \mathrm{~km}$ (14.9 miles) radius of the plant chose to evacuate (28). KI was not available on site, and sufficient KI for the surrounding population was not commercially available. In a heroic effort, sufficient liquid $\mathrm{KI}$ for the population within a 30-mile radius was produced, with the first shipment arriving two days after the accident and the full amount within five days. However, these liquid KI doses were never used $(28,29)$.

iii. What was the major route of ${ }^{131}$ I exposure?

This has not been well-studied, but it most likely included inhalation near the reactor and ingestion of contaminated water, milk, and vegetables at a distance. $i v$. What were the thyroid radiation doses?

This was not directly determined, but whole-body measurements of local residents did not find any detectable levels of radiation. The estimated average effective dose for residents living within $80 \mathrm{~km}(49.7$ miles) was $0.015 \mathrm{mSv}$, while the maximum effective dose was $0.85 \mathrm{mSv}$.

v. What were the long-term health effects in the exposed population?

Radiation doses to the surrounding population were minimal (30-33). As of 1995, there has been no increase in the overall risk of cancer among the exposed adult population, although there was a slightly increased risk of cancers of the bronchus, trachea, and lung in those exposed to higher background radiation and a slightly increased risk of leukemia in men. Children have not been separately evaluated (34). 


\section{B. Chernobyl (April 26, 1986)}

$i$. How much ${ }^{131} I$ was released into the atmosphere? Large amounts of ${ }^{131} \mathrm{I}$ isotopes were released from the Chernobyl nuclear accident (approximately $4.8 \times 10^{7} \mathrm{Ci}$ $\left[1,776,000 \mathrm{TBq}\right.$ ] of ${ }^{131} \mathrm{I}$ [which has a half-life of eight days] and $4.8 \times 10^{6} \mathrm{Ci}[177,600 \mathrm{TBq}]$ of ${ }^{133} \mathrm{I}$ [which has a half-life of $20.8 \mathrm{~h}$ ]) (35). Release occurred not as a one-time event, but over a period of 10 days.

ii. What was the response to the accident?

Measures to decrease ${ }^{131}$ I uptake by the thyroid gland in the surrounding population by evacuation, sheltering indoors, interdicting contaminated foodstuffs, or blocking thyroid uptake of ${ }^{131}$ I with KI were delayed, chaotic, and largely ineffective (36-39). Poland was the only country in the surrounding area to distribute KI at the population level following the accident. Approximately 17.5 million doses were given (10.5 million children and seven million adults) (40).

iii. What were the major routes of ${ }^{131}$ I exposure? The primary route of ${ }^{131} \mathrm{I}$ exposure was milk from cows feeding on vegetation contaminated from fallout. Contaminated vegetables played a smaller role, and inhalation of ${ }^{131}$ I was a significant route of thyroid exposure among the population close to the reactor at the time of the explosion $(36,41)$.

$i v$. What were the thyroidal radiation doses?

Thyroidal radiation doses were variable but generally higher among children and those in rural areas compared to adults in urban populations (41). In addition, the area around Chernobyl was relatively iodine deficient, leading to greater uptake of ${ }^{131}$ I by the thyroid gland compared to the other nuclear emergencies (42). Approximately $1 \%$ of children had thyroid ${ }^{131}$ I doses $>10 \mathrm{~Gy}$; the highest was 27 Gy (43). The mean absorbed thyroid doses were $0.49 \mathrm{~Gy}$ among evacuees and 0.10 Gy for residents of contaminated areas (36).

$v$. What were the long-term health effects in the exposed population?

More than 6000 cases of thyroid cancer have been detected in individuals who were children or adolescents living in the surrounding immediate area and countries at the time of the accident (36). Notably, none of these cases arose from those residing in Poland at the time, to whom KI was administered. Excess cases of thyroid cancer in exposed children were first detected after the accident in 1990. These are continuing to occur, albeit at a much slower rate, $>30$ years later. More importantly, analytic epidemiologic studies convincingly linked individual ${ }^{131}$ I thyroid doses from the Chernobyl accident and risk of thyroid cancer among exposed individuals $<18$ years of age. To date, there has been no detectable increase in thyroid cancer in those exposed as adults, or in leukemia or other solid tumors in the general population as a whole (36), although solid tumors may have a latency period of $>30$ years. There have been severe psychosocial problems related to evacuation, displacement, and fear of cancer (44).

$i v$. Why has thyroid cancer from Chernobyl only been detected in children?

The risk of thyroid cancer following exposure to both external (x-ray, gamma) and internal $\left({ }^{131} \mathrm{I}\right)$ radiation increases with the amount of radiation received by the thyroid (dose) and for the same thyroid dose, with younger age at exposure (i.e., children exposed in infancy have highest risks of thyroid cancer). Several factors are probably responsible for the increased incidence of thyroid cancer in children exposed to ${ }^{131} \mathrm{I}$ :

- Children consume more milk than adults and therefore receive higher thyroid doses if milk is contaminated. The area around Chernobyl is rural, and many families consumed milk from their own cows. Consumption of contaminated milk and vegetables was not interdicted until weeks after the accident and when substantial thyroid doses had already been received by the residents (36).

- The thyroid glands of children receive a greater radiation dose for a given uptake of ${ }^{131} \mathrm{I}$ than those of adults due to their smaller size.

- The thyroid glands of children are more radiosensitive than those of adults $(25,26,45)$.

\section{Fukushima (March 11, 2011)}

\section{$i$. How much ${ }^{131}$ I was released into the atmosphere?}

The details surrounding the Fukushima Daiichi nuclear accident have been extensively reviewed by the International Atomic Energy Agency (46). A large amount of ${ }^{131} \mathrm{I}$ was released following the Fukushima Daiichi nuclear power plant accident, which was initiated by a tsunami following the Tohoku earthquake on March 11, 2011. An estimated $3.2 \times 10^{6} \mathrm{Ci}(120 \mathrm{PBq})$ of ${ }^{131} \mathrm{I}$ was released from this nuclear accident into the environment, which constitutes approximately $10 \%$ of the amount released during the Chernobyl accident. Very little ${ }^{133} \mathrm{I}$ was released from the Fukushima plant after the accident (47).

ii. What was the response to the accident?

Seven hours after the accident, all residents within $3 \mathrm{~km}$ (1.9 miles) of the plant were evacuated, and those within $10 \mathrm{~km}$ (6.2 miles) were ordered to stay in their homes. The following day, the evacuation zone was extended to $20 \mathrm{~km}$ (12.4 miles). On April 22, 2011, there was a further evacuation of the most contaminated areas to the northwest of the plant. Six days after the accident, the government agencies began to monitor the radioactive content of tap water, milk, dairy products, and vegetables. Ten days after the accident, consumption of contaminated foods was prohibited (47). $\mathrm{KI}$ had not been predistributed to residents in the vicinity of the Fukushima Daiichi nuclear power plant. On March 13, 2011, the Central Nuclear Emergency Response headquarters recommended that evacuees $<40$ years of age take KI. However, the order was not properly communicated, and KI was only given in a few local areas $(48,49)$.

iii. What was the major route of ${ }^{131} I$ exposure? The major routes of ${ }^{131} \mathrm{I}$ exposure following the $\mathrm{Fu}-$ kushima accident varied based on location. Estimated thyroid doses in children from ingestion of ${ }^{131} \mathrm{I}$ in foodstuffs were relatively uniform in all locations, while internal radiation doses from inhalation and external radiation doses from radioisotopes deposited on the ground were higher in areas close to the plant (48). 
$i v$. What were the thyroid radiation doses?

Direct measurements of the thyroid radiation exposure in 1083 children found that $>50 \%$ had levels comparable with the background, $95.7 \%$ had received thyroid equivalent doses $<10 \mathrm{mSv}$, and the maximum thyroid equivalent dose in one child was $40-45 \mathrm{mSv}$. None had a level $>50 \mathrm{mSv}$ (47).

v. What were the long-term health effects in the exposed population?

Since it has been only a few years since the Fukushima accident and radiation-induced cancers have long latency, it is too early to estimate the potential long-term health effects from this nuclear accident. To date, there has been no detectable increase in cancer, including thyroid cancer, in either adults or children in the population around Fukushima $(35,50)$. The first round of thyroid screening, including ultrasound and fine-needle aspiration biopsies, has already been completed on the majority of the children in Fukushima Prefecture (2011-2014), and a significant number of thyroid cancers have been diagnosed (51). However, the high prevalence of thyroid cancer found at baseline examination in Fukushima Prefecture is similar to that found among unexposed children in three other areas of Japan where similar screening protocols have been used (51). Most of the cancers detected at baseline examination have been detected among adolescents and all within three years of the Fukushima accident, as opposed to early radiation-related cases following the Chernobyl accident that were not detected in younger children until five years after the accident (51).

The available estimates of thyroid radiation doses in the children around Fukushima are extremely low, especially when compared to the doses received from the Chernobyl accident. Therefore, it is less likely that there will be detectable increases in thyroid cancer incidence attributed to radiation exposure in the future, although an extensive screening program will continue $(45,48,52)$. As with the other nuclear emergencies, psychosocial effects have been significant, compounded by the effects of the accident's associated tsunami (48).

$i v$. What are the primary lessons deduced from the $F u$ kushima nuclear accident that can be used to inform U.S. recommendations for KI use?

The events and lessons learned from the Fukushima Daiichi nuclear power plant accident have been recently summarized (3). The following are the primary points from that publication:

- Control of the dietary pathway is feasible, even in the midst of a complex emergency setting. The airway pathway is not as easily ameliorated and poses a larger risk to newborns and very young children (53).

- Evacuation is not necessarily easy. The System for Prediction of Environmental Emergency Dose Information Network System (SPEEDI) in Japan was designed to be used in the event of a population-level emergency (54). However, following the Fukushima nuclear accident, data from the SPEEDI system were not available in a timely fashion, and some people were actually evacuated to areas with higher radiation levels, which later required a second evacuation (49), illustrating the potential limitation of relying on evacuation to minimize thyroid exposure to ${ }^{131} \mathrm{I}$ isotopes. In addition, nearly 300 hospitalized patients in the evacuation zone died during the evacuation process, with $>90 \%$ of these deaths occurring in senior citizens $>75$ years of age (55).

- A KI predistribution program to households was not in place at the time of the Fukushima nuclear accident. Although the Japanese government eventually recommended usage of KI, the estimated thyroid doses were below those of the World Health Organization (WHO) guidelines (56). Reports indicate that relatively few people in Japan actually ingested KI following the Fukushima emergency (57).

- In the time since the accident, Japan has initiated the predistribution of KI to residents living near actively operating nuclear power plants (58).

- The U.S. embassy in Tokyo advised Americans within 50 miles of the Fukushima nuclear plant to evacuate. The embassy also made KI available at two locations in Tokyo (about 150 miles from the site of the accident) to all Americans living or visiting Japan (59). The variances of the U.S. response from accepted guidelines and of the difference between the Japanese and American responses contributed to the overall sense of confusion in the aftermath of the Fukushima nuclear accident.

- The release of radioactive materials in Fukushima occurred over several days and was not a discrete, one-time event. This raises questions about how to use KI, especially among children and pregnant women, in a potentially similar future situation (3). In addition, the release (although not the amount of ${ }^{131} \mathrm{I}$ ) could have been much worse if the water cooling of the stored fuel rods had been lost (60).

\section{KI PLANNING AND INGESTION DURING A NUCLEAR EMERGENCY}

\section{What is the effectiveness of $\mathrm{Kl}$ ingestion in decreasing thyroid exposure to ${ }^{131} \mathrm{I}$ isotopes and subsequent thyroid cancer incidence following a nuclear emergency?}

The thyroid gland requires iodine to synthesize thyroid hormone and normally collects and retains $10-50 \%$ of ingested iodine, depending on the iodine content of the diet. Since there is no chemical difference between stable and radioactive iodine, the thyroid cannot discriminate between them and absorbs the same proportion of both from the circulation. As a result, the thyroid has a higher level of radiation exposure through ${ }^{131} \mathrm{I}$ than any other organ. The iodine content in KI, if ingested in the immediate period following a nuclear accident, acts as a competitive inhibitor to the uptake of ${ }^{131} \mathrm{I}$ by the thyroid gland. The half-life of ${ }^{131} \mathrm{I}$ is approximately eight days. Therefore, at least six to seven weeks of precautions might be necessary to minimize thyroidal uptake in the unlikely event that exposure persisted that long (i.e., $0.78 \%$ would be present at seven weeks). The ingestion of KI within one to two hours of ${ }^{131} \mathrm{I}$ inhalation is able to block $>90 \%$ of thyroidal uptake of ${ }^{131} \mathrm{I}$ (6), but it also has a substantial protective effect if taken three to four hours 
after exposure. In adults, ${ }^{131}$ I uptake by the thyroid can be markedly suppressed by a single dose of $30 \mathrm{mg}$ of KI. This suppression can be maintained with doses of at least $15 \mathrm{mg}$ once daily (61).

In general, the iodine content of iodinated table salt and other iodine-containing foods is insufficient to block the effects of thyroidal ${ }^{131}$ I uptake. Also, ingestion of KI does not protect the thyroid against the effects of internal or external exposure to other radioactive isotopes.

\section{What other mechanisms besides KI prophylaxis are recommended to decrease radiation exposure following a nuclear emergency?}

Besides KI prophylaxis, there are other mechanisms to decrease or limit the amount of radiation exposure following a nuclear emergency. These mechanisms include evacuation, sheltering, and avoiding contaminated food, milk, and water. These should ideally be guided by public health officials. Within the 10-mile EPZ from each nuclear reactor, the U.S. Federal Emergency Management Agency regularly disseminates emergency information, including instructions for evacuation and sheltering (62).

Within the 10-mile EPZ (considered the plume exposure pathway), individuals are subject to direct radiation exposure, and immediate measures, such as evacuation and sheltering in place, may be advised (20). Evacuation is important to minimize exposure to radiation; the greater the distance between the individual and the source of radiation, the less radiation will be received. It is difficult to predict how radiation will spread from a damaged plant, as it does not spread evenly and is affected by weather patterns, including wind, precipitation, and terrain. Following the Fukushima accident, the evacuation zone was expanded several times, with some residents unintentionally evacuating to areas of higher radiation exposure $(23,63)$. Concerns regarding evacuation also exist due to the potential for concomitant natural disasters that complicate rapid evacuation, as well as panic and communication difficulties that may result from concomitant natural disasters, acts of terrorism, or other events during a nuclear accident (49).

Other actions of importance during evacuation include closing all windows in vehicles and use of recirculated air. If possible, closing windows, doors, and fireplace dampers and turning off air-conditioning, vents, fans, and furnaces in homes prior to evacuating can limit radiation exposure (62). Items such as emergency food and water, essential medications, a battery-operated radio, and first-aid kit may be useful to bring, but should not delay evacuation when instructed. Similarly, attempts to obtain KI prophylaxis that may delay evacuation are not advised, further highlighting the importance of $\mathrm{KI}$ predistribution in areas surrounding nuclear reactors.

If unable to evacuate and/or instructed to shelter in place, it is advisable to bring pets inside, close and lock windows and doors, turn off air conditioning, vents, fans, and furnaces, and close fireplace dampers. Basements or other underground areas are best for avoiding radiation exposure, and individuals should stay inside until authorities instruct that it is safe to exit. If outdoors when a nuclear emergency occurs, individuals should shower as soon as possible and put shoes and clothing worn outdoors in a sealed plastic bag (62).
Within the $\geq 50$-mile radius EPZ, the primary concern is consumption of contaminated water and food supplies (i.e. the ingestion pathway). Significant dietary sources of iodine include cow's milk, cheese, eggs, fish, and shellfish, and contamination of these dietary sources can account for significant exposure to ${ }^{131}$ I following a nuclear reactor emergency. Following the Fukushima disaster, some residents outside the evacuation zone might have consumed contaminated local food or water before regulation measures were in effect. Due to the earthquake and ensuing tsunami, many residents experienced a shortage of fresh food and water, and local farmers had no means of knowing immediately whether their fields were contaminated (23). Nevertheless, control of contaminated food after the Fukushima accident was relatively effective, particularly when compared to the Chernobyl accident. Water sources can be contaminated following fallout of plume contaminants and could potential represent a significant exposure to radiation. If access to non-contaminated bottled water can be secured, the use of powdered milk, especially for children $<5$ years of age, is recommended for at least two to three weeks after containment of the nuclear accident (40). It is expected that the ingestion pathway would be less significant in the United States, as the multiple regulatory bodies including the Food and Drug Administration (FDA), Environmental Protection Agency, and United States Department of Agriculture would prevent consumption of contaminated food in large quantities through regulation of the food supply (15).

\section{When and at what doses should $K I$ be ingested following a nuclear emergency?}

The recommendations of the U.S. FDA regarding the doses of KI ingestion for the purposes of blocking thyroidal ${ }^{131} \mathrm{I}$ uptake following a nuclear emergency are summarized in Table 3. KI is most effective in the first few hours of exposure; ingestion of KI within one to two of ${ }^{131} \mathrm{I}$ inhalation is able to block $>90 \%$ of thyroidal uptake of ${ }^{131} \mathrm{I}(6)$. The thyroidal protection by KI lasts for approximately 24 hours, and thus it should be dosed daily if the risk of continuous ${ }^{131} \mathrm{I}$ exposure exists.

For pregnant females and neonates (in whom there is the potential for KI to suppress thyroid function with its associated detrimental effects), evacuation and sheltering should be emphasized over KI ingestion, particularly daily repeated ingestion. Other individuals who should potentially avoid KI prophylaxis include those with known iodine sensitivities to $\mathrm{KI}$, which does not necessarily include those with allergies or hypersensitivities to iodine or shellfish. Generally, allergies to iodinated contrast dye do not represent allergies to iodine itself, but rather to one of the various other components contained in contrast media. In addition, KI use should be cautioned in individuals with thyroid nodules, Graves' disease, and autoimmune thyroiditis, and in those with increased risk for cardiac arrhythmias.

\section{What forms of $\mathrm{KI}$ are currently available in the United States?}

Iosat $^{\mathrm{TM}}$, ThyroSafe ${ }^{\circledR}$, and ThyroShield ${ }^{\mathrm{TM}}$ are the commercially available FDA-approved KI products in the United States and can be obtained without a prescription. All U.S. products have a minimum shelf life of six years (64). The available formulations are $65 \mathrm{mg}$ (ThyroSafe ${ }^{\circledR}$ ) and $130 \mathrm{mg}$ 
Table 3. Threshold Thyroid ${ }^{131}$ I Exposures and Recommended KI Doses by Risk Group Following a Nuclear Emergency (Adapted from United States Food and Drug Administration)*

\begin{tabular}{|c|c|c|c|c|c|}
\hline & $\begin{array}{c}\text { Predicted } \\
\text { thyroid gland } \\
\text { exposure (cGy) }\end{array}$ & KI dose & $\begin{array}{l}\text { Number or } \\
\text { fraction of } \\
130 \mathrm{mg} \text { tablets }\end{array}$ & $\begin{array}{l}\text { Number or } \\
\text { fraction of } \\
65 \text { mg tablets }\end{array}$ & $\begin{array}{c}m L \text { of oral } \\
\text { solution, } \\
65 \mathrm{mg} / \mathrm{mL}^{\mathrm{c}}\end{array}$ \\
\hline Adults >40 years of age & $>500$ & $130 \mathrm{mg}$ & 1 & 2 & $2 \mathrm{~mL}$ \\
\hline Adults 18-40 years of age & $>10$ & $130 \mathrm{mg}$ & 1 & 2 & $2 \mathrm{~mL}$ \\
\hline Pregnant or lactating women & $>5$ & $130 \mathrm{mg}$ & 1 & 2 & $2 \mathrm{~mL}$ \\
\hline Adolescents $12-18$ years of age ${ }^{a}$ & $>5$ & $65 \mathrm{mg}$ & $1 / 2$ & 1 & $1 \mathrm{~mL}$ \\
\hline Children $3-12$ years of age & $>5$ & $65 \mathrm{mg}$ & $1 / 2$ & 1 & $1 \mathrm{~mL}$ \\
\hline Children 1 month to 3 years of age & $>5$ & $32 \mathrm{mg}$ & $\begin{array}{l}\text { Use KI oral } \\
\text { solution }\end{array}$ & $1 / 2$ & $0.5 \mathrm{~mL}$ \\
\hline Infants birth to 1 month of age & $>5$ & $16 \mathrm{mg}$ & $\begin{array}{l}\text { Use KI oral } \\
\text { solution }\end{array}$ & $\begin{array}{l}\text { Use KI oral } \\
\text { solution }^{\mathrm{b}}\end{array}$ & $0.25 \mathrm{~mL}$ \\
\hline
\end{tabular}

All doses are to be taken as soon as possible (ideally within the first few hours) following a nuclear accident and thereafter daily until the risk of significant exposure to ${ }^{131} \mathrm{I}$ by either inhalation or ingestion no longer exists, as advised by authorities.

*Reference (64).

aAdolescents approaching adult size ( $>150 \mathrm{lbs})$ should receive the full adult dose $(130 \mathrm{mg})$

${ }^{\mathrm{b}} \mathrm{KI}$ oral solution is supplied in $1 \mathrm{oz}(30 \mathrm{~mL})$ bottles with a dropper marked for $1,0.5$, and $0.25 \mathrm{~mL}$ dosing. Each $\mathrm{mL}$ of oral solution contains $65 \mathrm{mg}$ of $\mathrm{KI}$.

${ }^{\mathrm{c}}$ See the Home Preparation Procedure for Emergency Administration of Potassium Iodide Tablets to Infants and Small Children (68).

(Iosat $^{\mathrm{TM}}$ ) oral tablets and liquid KI (Thyroshield ${ }^{\mathrm{TM}}$ ). The liquid formulations of KI are no longer offered by the U.S. NRC (20).

\section{What are the major reasons for and against the predistribution of $\mathrm{KI}$ to be consumed in the event of a nuclear emergency?}

\section{A. What are the arguments for predistribution?}

- KI effectively reduces thyroidal exposure to ${ }^{131} \mathrm{I}$ isotopes.

- To be effective, KI must be taken within a few hours of ${ }^{131}$ I exposure.

- If evacuation, sheltering in place, and avoidance of contaminated food are not possible, KI ingestion is effective in reducing thyroid exposure to ${ }^{131} \mathrm{I}$ and is associated with very few possible side effects.

- The primary purpose of KI predistribution is to reduce ${ }^{131}$ I exposure to the thyroid from inhalation, which remains a risk regardless of the ability to control contaminated food intake at later stages.

- Even if the food pathway is completely controlled, infants may not be able to avoid the ingestion of contaminated raw milk, most likely from local cows. Failure of interdiction of contaminated products in the commercial market would be a less likely route of exposure.

- Even if radiation exposure thresholds are not exceeded and public health officials do not recommend it, demand for KI will be high following a nuclear emergency.

- In the absence of predistribution, those outside of official evacuation zones may elect to evacuate rather than shelter in place. The message of "take KI and shelter in place" may ameliorate this potentially inevitable factor.

- If $\mathrm{KI}$ is not distributed in advance, evacuation for some people could be delayed.
- As was reported following the Fukushima accident, some people may be unintentionally evacuated to locations with even higher levels of radiation exposure.

B. What are the arguments against and/or caveats regarding predistribution?

- KI does not protect against external radiation and radioactive isotopes other than ${ }^{131} \mathrm{I}$.

- KI may give a false sense of security, and some people may not follow official advice to evacuate.

- Effective control of the food (milk) pathway will reduce some risk of ${ }^{131} \mathrm{I}$ exposure.

- The risks of exposure to ${ }^{131} \mathrm{I}$ isotopes, particularly from inhalation, are expected to be lower (although the extent of this is unknown) in iodine-replete populations such as the United States and Japan than in the Chernobyl-exposed population, which was relatively iodine deficient.

- Even if KI is predistributed, depending on the time and day of the week, many people may not have timely access to it or remember where the KI was stored.

\section{What is the evidence guiding the deployment of $\mathrm{Kl}$, including $\mathrm{KI}$ predistribution, at various distances around nuclear power plants?}

Consistent with its 2002 statement (2), the ATA recommends that the government institute distance-based coverage (0-10 miles and >10-50 miles; Table 4$)$, as modified by local factors that include the feasibility of rapid evacuation and more sophisticated and reliable climatologic models. Compared with the 2002 statement, the current recommended radii for KI use are lower. Pictorially, Figure 1 shows the current active U.S. nuclear power plants and the 10- and 50 -mile radii of potential impact surrounding each plant.

In the present statement, the ATA recommends a minimum 10 -mile radius for KI predistribution and that states should not only consider (as stated in the NRC recommendation) (4) but be required to include predistribution of $\mathrm{KI}$ as a protective 
TABle 4. Recommendations by the American

Thyroid AsSOciation FOR THE PREDISTRIBUtion, StockPILING, AND AvaILABILITY OF KI to INDIVIDUALS Residing NeAR an ACTIVELy Operating U.S. Nuclear Power Plant

\begin{tabular}{lcc}
\hline Ring & $\begin{array}{c}\text { Distance } \\
\text { (miles) }\end{array}$ & \multicolumn{1}{c}{ Action } \\
\hline 1 & $0-10$ & $\begin{array}{c}\text { Distribute KI in advance } \\
\text { ("predistribute") to individual } \\
\text { households, with extra stockpiles } \\
\text { stored at emergency reception } \\
\text { centers } \\
\end{array}$ - $\begin{array}{l}\text { Stockpile KI in local public facilities } \\
\text { such as schools, hospitals, clinics, } \\
\text { post offices, and police and fire } \\
\text { stations for distribution upon } \\
\text { notification by local health officials }\end{array}$ \\
&
\end{tabular}

measure for the general public. In comparison, according to the Organization for Economic Cooperation and Development of the Nuclear Energy Agency quoted in the 2004 National Academy of Sciences report (4), planning zones for stable iodine predistribution in most countries range between 2.5 and 12.4 miles.

The choice of radii and respective KI actions are based primarily on the likelihood of thyroid exposure to ${ }^{131} \mathrm{I}$ through the inhalation route. KI prophylaxis is the most effective countermeasure when the inhalation-exposure route is the major contributor to thyroid activity (i.e., within 10 miles). Thyroid blocking is very relevant in the early phase following an accident during the passage of a radioactive cloud. Only those in the direct path of the plume would be in immediate danger. As the plume moves away from the release point, it dissipates, and the concentration of radioactive materials decreases, as well as the probability of thyroid doses from inhalation approaching intervention levels. Iodine blockade will rarely be used as a stand-alone protective action in this situation and will likely be combined with sheltering or evacuation. The 10-mile radius of KI predistribution represents the minimum level of precaution, as local conditions might dictate a larger and not necessarily circular perimeter from the site of the nuclear accident. Other relevant factors include local meteorologic conditions or the likely possibility that many large urban areas straddle the 10-mile perimeter.

Given the potential difficulty in accessing $\mathrm{KI}$ in the event of an emergency, the ATA recommends the stockpiling of KI in local public facilities such as schools, hospitals, clinics, post offices, and police and fire stations for distribution upon notification by local health officials for those residing in the 10- to 50-mile radii. In areas beyond 10 miles and particularly beyond 50 miles of the nuclear facility, the most likely route of exposure will be through the ingestion pathway. In this instance, restricting the production and consumption of foodstuffs will be more effective (56). For example, while the radioactive plume from the Chernobyl accident reached Bryansk, Russia (150 miles away from the Chernobyl nuclear power plant) and significant excess of thyroid cancer was observed in the region, it was estimated that most of the thyroid dose was received from consumption of contaminated milk and dairy products and not from inhalation (65).

Finally, for all populations, KI should be readily available from the U.S. Department of Health and Human Services' National Pharmaceutical Stockpile in the event of a nuclear emergency.

\section{What are the potential risks of $K I$ use following a nuclear emergency?}

The acute Wolff-Chaikoff effect, which is characterized by a temporary decrease of thyroid hormone synthesis upon exposure to excess iodine, protects against the adverse consequences of the high-iodine load associated with KI ingestion. However, in certain individuals, particularly those with a history of thyroid disease (including those with thyroid nodules) and in infants, in whom the thyroid gland is not yet fully mature, escape from the acute Wolff-Chaikoff effect does not necessarily occur, and thus ingestion of excess iodine has the potential to induce thyroid dysfunction in susceptible individuals (66). Pregnant women and infants are the
FIG. 1. Map showing 10and 50-mile radii of potential impact surrounding each currently active U.S. nuclear power plant.

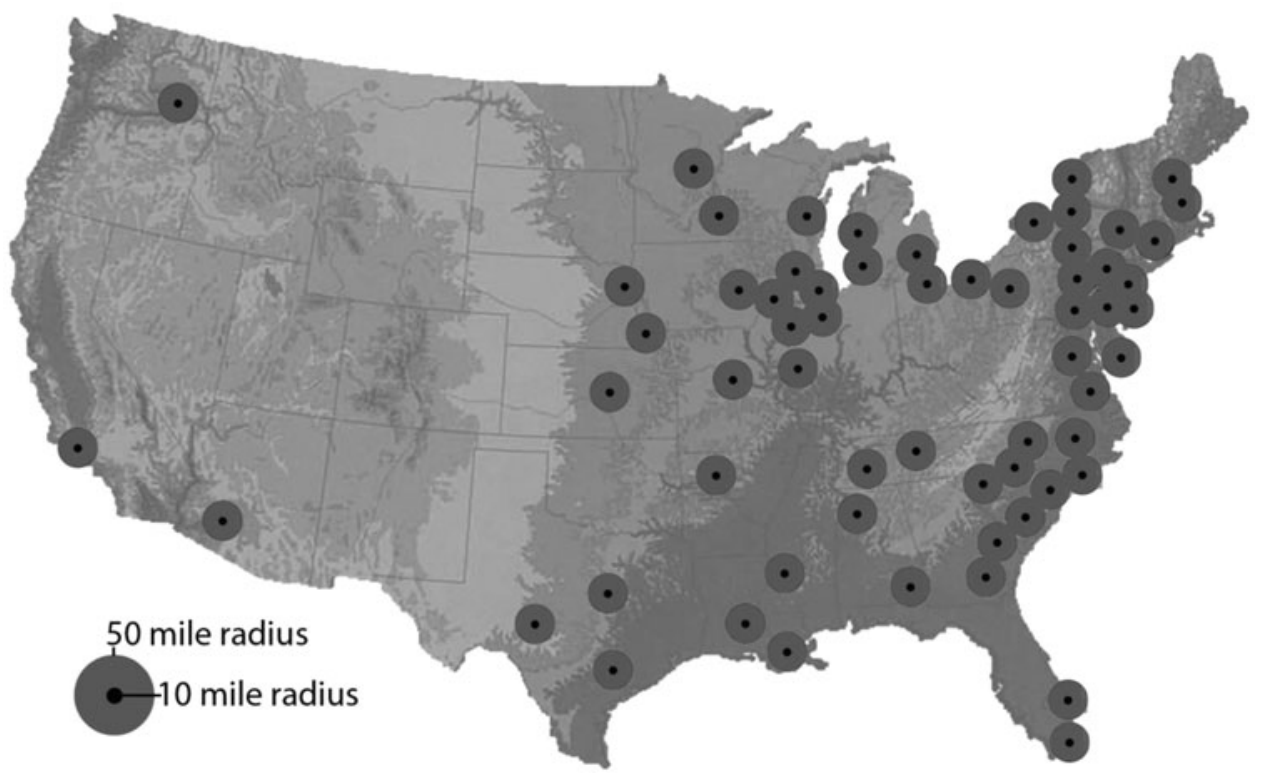


groups most vulnerable to these potential effects, given the importance of normal thyroid hormone levels for early somatic and neurodevelopment. However, to date, there is only a single "field study" reporting on the clinical impact of KI prophylaxis on serum thyroid hormone status, published from data collected on 35,000 people (one-third of them children) in Poland following the Chernobyl accident (40). An acute, temporary increase in serum thyrotropin concentrations was found in $0.37 \%$ of newborns, with the remainder of the population showing no adverse impact on thyroid function (40).

The U.S. Centers for Disease Control and Prevention and the U.S. Department of Health and Human Services have provided guidance on the use of KI ingestion after a nuclear emergency among lactating women $(6,67)$. Breastfeeding women should take only a single dose of KI, unless other means of radiation protection (evacuation, sheltering, and control of contaminated food intake) are unavailable. If possible, breastfeeding women are encouraged to stop nursing and switch feeding of their infant with an alternative food source during the acute exposure period.

\section{What are the recommendations of the ATA for the distribution and use of $K I$ in the event of a nuclear emergency in the United States?}

- The major ATA recommendations for KI distribution are summarized in Table 4, while KI doses and time course of use in the event of a nuclear emergency are summarized in Table 3.

- KI use should be part of an emergency plan that includes evacuation, sheltering, and the avoidance of contaminated food, milk, and water ingestion in the event of a nuclear emergency.

- The highest priority for KI use and all other emergency measures should be given to babies, children up to 18 years of age, and pregnant women.

- Within a minimum of 10 miles of an actively operating nuclear power plant, KI should be predistributed to individual households. Emergency reception areas immediately outside of this radius should also be equipped with extra KI stockpiles. This should be a required rather than an optional measure.

- For individual households within 50 miles of an operating nuclear power plant, KI should be stockpiled in local public facilities such as schools, hospitals, clinics, post offices, pharmacies, and police and fire stations for distribution upon notification by local health officials.

- Overall, KI should be ready to be made available to the U.S. population from the U.S. Department of Health and Human Services' National Pharmaceutical Stockpile, but used only under regulatory guidance.

\section{ACKNOWLEDGMENTS}

This statement was approved by the American Thyroid Association Board of Directors. It was supported by $\mathrm{NIH}$ K23HD068552 (A.M.L.). This work was prepared by the authors in their personal capacities. The opinions expressed in this article are the authors' own and do not reflect the view of UCLA, the VA Healthcare System, the NIH (A.M.L.); Children's Hospital of Philadelphia, University of Pennsylvania, Perelman School of Medicine (A.J.B.); University of Messina School of Medicine, University hospital Policlinico
G Martino (S.B.); Division of Cancer Epidemiology and Genetics, National Cancer Institute, National Institutes of Health, Department of Health and Human Services, United States government (A.V.B.); Beth Israel Deaconess Medical Center (J.V.H.); Weill Cornell Medical College (Hurley); Texas Tech University Health Sciences Center (S.A.M.); University of Illinois College of Medicine (A.B.S.); SUNY Downstate Medical Center (K.S.); or Northwestern University (D.J.T.).

\section{AUTHOR DISCLOSURE STATEMENT}

No competing financial interests exist.

\section{REFERENCES}

1. Becker DV, Braverman LE, Dunn JT, Gaitan E, Gorman C, Maxon H, Schneider AB, Van Middlesworth L, Wolff J 1984 The use of iodine as a thyroidal blocking agent in the event of a reactor accident. Report of the Environmental Hazards Committee of the American Thyroid Association. JAMA 252:659-661.

2. American Thyroid Association. American Thyroid Association endorses potassium iodide for radiation emergencies. Available at: www.thyroid.org/ata-endorses-potassiumiodide-for-radiation-emergencies/ (accessed August 15, 2016).

3. Schneider AB, Smith JM 2012 Potassium iodide prophylaxis: what have we learned and questions raised by the accident at the Fukushima Daiichi Nuclear Power Plant. Thyroid 22:344-346.

4. Committee to Assess the Distribution and Administration of Potassium Iodide in the Event of a Nuclear Accident Incident; Board on Radiation Effects Research; Division on Earth and Life Sciences; National Research Council 2004 Distribution and Administration of Potassium Iodide in the Event of a Nuclear Incident. National Academies Press, Washington, DC.

5. Reiners C, Schneider R, Akashi M, Akl EA, Jourdain JR, Li C, Murith C, Van Bladel L, Yamashita S, Zeeb H, Vitti P, Carr Z 2016 The first meeting of the WHO guideline development group for the revision of the WHO 1999 guidelines for iodine blocking. Radiat Prot Dosimetry 171: 47-56.

6. U.S. Department of Health \& Human Services Radiation Emergency Medical Management. Potassium iodide. Available at: www.remm.nlm.gov/potassiumiodide.htm (accessed August 18, 2016).

7. Schneider M, Froggart A. The World Nuclear Industry Status Report. Available at: www.worldnuclearreport.org/2015-.html (accessed September 18, 2016).

8. International Atomic Energy Association. The database on nuclear power reactors. Available at: www.iaea.org/pris (accessed July 11, 2016).

9. United States Nuclear Regulatory Commission. Map of power reactor sites. Available at: www.nrc.gov/reactors/ operating/map-power-reactors.html (accessed August 3, 2016).

10. United States Nuclear Regulatory Commission. Backgrounder on research and test reactors. Available at: www .nrc.gov/reading-rm/doc-collections/fact-sheets/researchreactors-bg.html (accessed September 1, 2016).

11. National Center for Disaster Preparedness. Nuclear power plants and earthquake risk. Available at: http://ncdp .columbia.edu/library/mapsmapping-projects/nuclearpower-plants-earthquake-risk/ (accessed July 11, 2016). 
12. U.S. Food and Drug Administration. Public Health Safety and Bioterrorism Preparedness and Response Act of 2002 (PL107-188), Letter from Center Director. Available at: www .fda.gov/Food/GuidanceRegulation/GuidanceDocuments RegulatoryInformation/FoodDefense/ucm111086.htm (accessed August 24, 2016).

13. Endocrinology \& Metabolism News 2008 White House Decision on Potassium Iodide Distribution Leaves Many Baffled. J Clin Endocrinol Metab 93(3):17a-20a; DOI: https://doi.org/10.1210/jcem.93.3.9993.

14. United States Nuclear Regulatory Commission. Consideration of potassium iodide in emergency planning. Available at: www.nrc.gov/about-nrc/emerg-preparedness/aboutemerg-preparedness/potassium-iodide.html\#distribution-ki (accessed August 25, 2016).

15. Fitzgerald J, Wollner SB, Adalja AA, Morhard R, Cicero A, Inglesby TV 2012 After Fukushima: managing the consequences of a radiological release. Biosecur Bioterror 10:228-236.

16. European Commission. Radiation Protection No 165Medical effectiveness of iodine prophylaxis in a nuclear reactor emergency situation and overview of European practices. Available at: https://ec.europa.eu/energy/sites/ ener/files/documents/165.pdf (accessed August 3, 2016).

17. United States Nuclear Regulatory Commission 2011 Developing an Emergency Risk Communication (ERC)/Joint Information Center (JIC) Plan for a Radiological Emergency. Center for Risk Communication, New York, New York.

18. Murakami M, Ono K, Tsubokura M, Nomura S, Oikawa T, Oka T, Kami M, Oki T 2015 Was the risk from nursinghome evacuation after the Fukushima accident higher than the radiation risk? PLoS One 10:e0137906.

19. Tanigawa K, Hosoi Y, Hirohashi N, Iwasaki Y, Kamiya K 2012 Loss of life after evacuation: lessons learned from the Fukushima accident. Lancet 379:889-891.

20. United States Nuclear Regulatory Commission. Emergency planning zones. Available at: www.iaea.org/pris (accessed June 23, 2016).

21. United Nations Scientific Committee on the Effects of Atomic Radiation. UNSCEAR sssessments of the Chernobyl accident. Available at: www.unscear.org/unscear/en/ chernobyl.html (accessed August 3, 2016).

22. Braverman ER, Blum K, Loeffke B, Baker R, Kreuk F, Yang SP, Hurley JR 2014 Managing terrorism or accidental nuclear errors, preparing for iodine-131 emergencies: a comprehensive review. Int $\mathbf{J}$ Environ Res Public Health 11:4158-4200.

23. Dauer LT, Zanzonico P, Tuttle RM, Quinn DM, Strauss HW 2011 The Japanese tsunami and resulting nuclear emergency at the Fukushima Daiichi power facility: technical, radiologic, and response perspectives. J Nucl Med 52:1423-1432.

24. Cardis E, Howe G, Ron E, Bebeshko V, Bogdanova T, Bouville A, Carr Z, Chumak V, Davis S, Demidchik Y, Drozdovitch V, Gentner N, Gudzenko N, Hatch M, Ivanov V, Jacob P, Kapitonova E, Kenigsberg Y, Kesminiene A, Kopecky KJ, Kryuchkov V, Loos A, Pinchera A, Reiners C, Repacholi M, Shibata Y, Shore RE, Thomas G, Tirmarche M, Yamashita S, Zvonova I 2006 Cancer consequences of the Chernobyl accident: 20 years on. J Radiol Prot 26:127-140.

25. Faggiano A, Coulot J, Bellon N, Talbot M, Caillou B, Bidart JM, Schlumberger M 2004 Age-dependent variation of follicular size and expression of iodine transporters in human thyroid tissue. J Nucl Med 45:232-237.
26. Saad AG, Kumar S, Ron E, Lubin JH, Stanek J, Bove KE, Nikifurov YE 2006 Proliferative activity of human thyroid cells in various age groups and its correlation with the risk of thyroid cancer after radiation exposure. J Clin Endocrinol Metab 91:2672-2677.

27. Ohtsuru A, Tanigawa K, Kumagai A, Niwa O, Takamura N, Midorikawa S, Nollet K, Yamashita S, Ohto H, Chhem RK, Clarke M 2015 Nuclear disasters and health: lessons learned, challenges, and proposals. Lancet 386:489-497.

28. Report of the President's Commission on the accident at Three Mile Island. Available at: www.threemileisland.org/ downloads/188.pdf (accessed August 22, 2016).

29. Small WE 1979 Mobilizing for Three Mile Island-the disaster that wasn't. Am Pharm 19:8-9.

30. Radiation and health effects. A report of the TMI-2 accident and related health studies. Available at: www .threemileisland.org/downloads/224.pdf (accessed August 20, 2016).

31. United States Nuclear Regulatory Commission. Backgrounder on Three Mile Island accident. Available at: www .nrc.gov/reading-rm/doc-collections/fact-sheets/3mile-isle .html (accessed August 22, 2016).

32. Goyal N, Camacho F, Mangano J, Goldenberg D 2012 Thyroid cancer characteristics in the population surrounding Three Mile Island. Laryngoscope 122:1415-1421.

33. Levin RJ, De Simone NF, Slotkin JF, Henson BL 2013 Incidence of thyroid cancer surrounding Three Mile Island nuclear facility: the 30-year follow-up. Laryngoscope 123: 2064-2071.

34. Han YY, Youk AO, Sasser H, Talbott EO 2011 Cancer incidence among residents of the Three Mile Island accident area: 1982-1995. Environ Res 111:1230-1235.

35. Nagataki S 2014 Radiation Health Effects and Countermeasures: Lessons from Past Nuclear Disasters from Atomic Bomb to Fukushima. Maruzen Publishing Co. Ltd., Tokyo, Japan.

36. United Nations Scientific Committee on the Effects of Atomic Radiation. Sources and effects of ionizing radiation. Report to the general assembly 2008. Annex D: Health effects due to radiation from the Chernobyl accident. Available at: www.unscear.org/docs/reports/2008/11-80076_ Report_2008_Annex_D.pdf (accessed August 17, 2016).

37. Saenko V, Ivanov V, Tsyb A, Bogdanova T, Tronko M, Demidchik Y, Yamashita S 2011 The Chernobyl accident and its consequences. Clin Oncol (R Coll Radiol) 23:234243.

38. Likhtarev IA, Chumack VV, Repin VS 1994 Analysis of the effectiveness of emergency countermeasures in the 30$\mathrm{km}$ zone during the early phase of the Chernobyl accident. Health Phys 67:541-544.

39. Mettler F, Royal H, Hurley J 1992 Administration of stable iodine to the population around the Chernobyl nuclear power plant. J Radiol Prot 12:159-165.

40. Nauman J, Wolff J 1993 Iodine prophylaxis in Poland after the Chernobyl reactor accident: benefits and risks. Am J Med 94:524-532.

41. Bouville A, Likhtarev IA, Kovgan LN, Minenko VF, Shinkarev SM, Drozdovitch VV 2007 Radiation dosimetry for highly contaminated Belarusian, Russian and Ukrainian populations, and for less contaminated populations in Europe. Health Phys 93:487-501.

42. Shakhtarin VV, Tsyb AF, Stepanenko VF, Orlov MY, Kopecky KJ, Davis S 2003 Iodine deficiency, radiation dose, and the risk of thyroid cancer among children and 
adolescents in the Bryansk region of Russia following the Chernobyl power station accident. Int J Epidemiol 32:584591.

43. Likhtarov I, Kovgan L, Vavilov S, Chepurny M, Bouville A, Luckyanov N, Jacob P, Voillequé P, Voigt G 2005 PostChornobyl thyroid cancers in Ukraine. Report 1: estimation of thyroid doses. Radiat Res 163:125-136.

44. Bromet EJ, Havenaar JM, Guey LT 2011 A 25 year retrospective review of the psychological consequences of the Chernobyl accident. Clin Oncol (R Coll Radiol) 23:297305.

45. Ron E, Lubin JH, Shore RE, Mabuchi K, Modan B, Pottern LM, Schneider AB, Tucker MA, Boice JD 1995 Thyroid cancer after exposure to external radiation: a pooled analysis of seven studies. Radiat Res 141:259-277.

46. International Atomic Energy Agency. The Fukushima Daiichi accident. Available at: www-pub.iaea.org/books/ IAEABooks/10962/The-Fukushima-Daiichi-Accident (accessed March 3, 2017).

47. Nagataki S, Takamura N 2014 A review of the Fukushima nuclear reactor accident: radiation effects on the thyroid and strategies for prevention. Curr Opin Endocrinol Diabetes Obes 21:384-393.

48. World Health Organization. Preliminary dose estimation from the nuclear accident after the 2011 great East Japan earthquake and tsunami. Available at: www.who.int/entity/ ionizing_radiation/pub_meet/fukushima_dose_assessment/ en/ (accessed August 17, 2016).

49. Shimura T, Yamaguchi I, Terada H, Robert Svendsen E, Kunugita N 2015 Public health activities for mitigation of radiation exposures and risk communication challenges after the Fukushima nuclear accident. J Radiat Res 56:422429.

50. Ohira T, Takahashi H, Yasumura S, Ohtsuru A, Midorikawa S, Suzuki S, Fukushima T, Shimura H, Ishikawa T, Sakai A, Yamashita S, Tanigawa K, Ohto H, Abe M, Group FHMS 2016 Comparison of childhood thyroid cancer prevalence among 3 areas based on external radiation dose after the Fukushima Daiichi nuclear power plant accident: the Fukushima Health Management Survey. Medicine (Baltimore) 95:e4472.

51. Suzuki S, Fukushima T, Midorikawa S, Shimura H, Matsuzuka T, Ishikawa T, Takahashi H, Ohtsuru A, Sakai A, Hosoya M, Yasumura S, Nollet KE, Ohira T, Ohto H, Abe M, Kamiya K, Yamashita S 2016 Comprehensive survey results of childhood thyroid ultrasound examinations in Fukushima in the first four years after the Fukushima Daiichi nuclear power plant accident. Thyroid 26:843-851.

52. United Nations Scientific Committee on the Effects of Atomic Radiation. Report to the General Assembly 2013. Scientific annex A: levels and effects of radiation exposure due to the nuclear accident after the 2011 great East-Japan earthquake and tsunami. Available at: www.unscear.org/ docs/reports/2013/13-85418_Report_2013_Annex_A.pdf (accessed August 22, 2016).

53. Tani K, Kurihara O, Kim E, Yoshida S, Sakai K, Akashi M 2015 Implementation of iodine biokinetic model for interpreting I-131 contamination in breast milk after the $\mathrm{Fu}$ kushima nuclear disaster. Sci Rep 5:12426.

54. Misawa M, Nagamori F 2008 System for prediction of environmental emergency dose information network system. Fujitsu Sci Tech J 44:377-398.
55. Zhang H, Yan W, Oba A, Zhang W 2014 Radiation-driven migration: the case of Minamisoma City, Fukushima, Japan, after the Fukushima nuclear accident. Int $\mathbf{J}$ Environ Res Public Health 11:9286-9305.

56. World Health Organization. Guidelines for Iodine Prophylaxis Following Radiation Accidents. Available at: www .who.int/ionizing_radiation/pub_meet/Iodine_Prophylaxis_ guide.pdf (accessed August 18, 2016).

57. Miska H 2016 Evaluation of the response to the Fukushima accident. Health Phys 111:218-222.

58. Yoshida S, Ojino M, Ozaki T, Hatanaka T, Nomura K, Ishii M, Koriyama K, Akashi M 2014 Guidelines for iodine prophylaxis as a protective measure: information for physicians. Japan Med Assoc J 57:113-123.

59. Simon SI, Coleman CN, Noska MA, Bowman T 2012 Response of the U.S. Department of Health and Human Services in protecting civilian Americans in Japan during the Fukushima nuclear crisis. Health Phys 102(5).

60. Stone R 2016 Nuclear safety. Near miss at Fukushima is a warning for U.S. Science 352:1039-1040.

61. Sternthal E, Lipworth L, Stanley B, Abreau C, Fang SL, Braverman LE 1980 Suppression of thyroid radioiodine uptake by various doses of stable iodine. N Engl J Med 6: $1083-1088$.

62. United States Federal Emergency Management Agency (FEMA). Nuclear reactor emergency preparedness. Available at: www.nukepills.com/docs/FEMA_Nuclear_Power_ Plant_Emergency.pdf (accessed September 18, 2016).

63. Onishi N, Fackler M 2011 Japan held nuclear data, leaving evacuees in peril. New York Times, August 8.

64. United States Food and Drug Administration. Frequently asked questions on potassium iodide (KI). Available at: www.fda.gov/Drugs/EmergencyPreparedness/Bioterrorism andDrugPreparedness/ucm072265.htm (accessed August 3, 2016).

65. Davis S, Stepanenko V, Rivkind N, Kopecky KJ, Voillequé P, Shakhtarin V, Parshkov E, Kulikov S, Lushnikov E, Abrosimov A, Troshin V, Romanova G, Doroschenko V, Proshin A, Tsyb A 2004 Risk of thyroid cancer in the Bryansk Oblast of the Russian Federation after the Chernobyl Power Station accident. Radiat Res 162:241-248.

66. Leung AM, Braverman LE 2014 Consequences of excess iodine. Nat Rev Endocrinol 10:136.

67. United States Centers for Disease Control and Prevention. Emergency preparedness and response: Breastfeeding. Available at: http://emergency.cdc.gov/radiation/breastfeeding .asp (accessed August 18, 2016).

68. U.S. Food and Drug Administration. Potassium iodide ("KI"): instructions to make potassium iodide solution for use during a nuclear emergency (liquid form). Available at: www.fda.gov/Drugs/EmergencyPreparedness/Bioterrorism andDrugPreparedness/ucm072248.htm (accessed August 3, 2016).

Address correspondence to: Angela M. Leung, MD, MSc Division of Endocrinology (111D) VA Greater Los Angeles Healthcare System 11301 Wilshire Blvd Los Angeles, CA 90073

E-mail: AMLeung@mednet.ucla.edu 